\title{
Conductivity and Hall effect measurements on intentionally undoped and doped AIGaN/GaN heterostructures before and after passivation
}

\author{
J. Bernát, P. Javorka, M. Marso, and P. Kordoša) \\ Institute of Thin Films and Interfaces (ISG-1), Research Centre Jülich, D-52425 Jülich, Germany
}

(Received 20 August 2003; accepted 3 November 2003)

\begin{abstract}
Conductivity and Hall effect measurements were performed before and after $\mathrm{Si}_{3} \mathrm{~N}_{4}$ passivation of intentionally undoped and doped $\mathrm{AlGaN} / \mathrm{GaN}$ heterostructures on $\mathrm{Si}$ and $\mathrm{SiC}$ substrates. An increase of the sheet carrier density (up to $\sim 30 \%$ ) and a slight decrease of the electron mobility (less than $10 \%)$ are found in all samples after passivation. The passivation induced sheet carrier density is $1.5-2 \times 10^{12} \mathrm{~cm}^{-2}$ in undoped samples and only $0.7 \times 10^{12} \mathrm{~cm}^{-2}$ in $5-10 \times 10^{18} \mathrm{~cm}^{-3}$ doped samples. The decrease of the electron mobility after passivation is slightly lower in highly doped samples. The channel conductivity in both types of unpassivated samples on $\mathrm{Si}$ and SiC substrates increases with an increase in doping density. After passivation, a well-resolved increase of channel conductivity is observed in the undoped or lightly doped samples and nearly the same channel conductivity results in the highly doped samples. (c) 2003 American Institute of Physics.
\end{abstract}

[DOI: $10.1063 / 1.1637154]$

It is well known that AlGaN/GaN high-electron mobility transistors (HEMTs) exhibit significant radio-frequency (rf) dispersion $^{1,2}$ that is attributed to trapping effects caused mainly by surface states and partially by buffer/active-layer traps. ${ }^{2,3}$ Surface passivation has been found to reduce current slump and microwave power degradation of intentionally undoped AlGaN/GaN HEMTs. ${ }^{3}$ However, the influence of passivation on device performance is not fully clear yet ${ }^{4}$ and application of various insulators, mainly $\mathrm{SiO}_{2}$ and $\mathrm{Si}_{3} \mathrm{~N}_{4}$, is currently under detailed investigation. Mostly intentionally undoped devices are studied and an increase of carrier density in the channel is assumed on the basis of the drain current and increase in transconductance after passivation. ${ }^{3-8}$ The only published Hall effect data show an increase of carrier density and a decrease of mobility, resulting in lower channel conductivity of undoped and doped AlGaN/GaN heterostructures after $\mathrm{SiO}_{2}$ passivation. ${ }^{9}$ Recently, degradation of the rf performance after $\mathrm{SiO}_{2}$ passivation and overall performance improvement after $\mathrm{Si}_{3} \mathrm{~N}_{4}$ passivation were observed. ${ }^{10}$ Similar differences like an increase ${ }^{6}$ or a decrease $^{7}$ of gate leakage current and an increase ${ }^{5}$ as well as a decrease of $^{3,7}$ cut off frequencies of AlGaN/GaN HEMTs after $\mathrm{Si}_{3} \mathrm{~N}_{4}$ passivation were reported. All these underscore the importance of further detailed studies of passivation in order to optimize the performance of GaN-based devices.

In this letter, we report on passivation-induced changes in the transport properties of $\mathrm{AlGaN} / \mathrm{GaN}$ heterostructures. Conductivity and Hall effect measurements before and after $\mathrm{Si}_{3} \mathrm{~N}_{4}$ passivation of heterostructures grown on $\mathrm{Si}$ and $\mathrm{SiC}$ substrates were performed. It is shown that the passivation has different impact on intentionally undoped and doped samples.

$\mathrm{AlGaN} / \mathrm{GaN}$ heterostructures were grown on high resistivity $\mathrm{Si}(111)$ and semi-insulating $\mathrm{SiC}$ substrates by metalorganic chemical vapor deposition. Intentionally undoped

${ }^{a)}$ Electronic mail: p.kordos@fz-juelich.de structures consisted of $25 \mathrm{~nm}$ undoped AlGaN (Si substrate) or $30 \mathrm{~nm}$ undoped $\mathrm{AlGaN}$ and $3 \mathrm{~nm}$ undoped GaN cap (SiC substrate) grown on top of a GaN buffer. Doped structures consisted of a $5 \mathrm{~nm}$ undoped AlGaN spacer, a $10 \mathrm{~nm}$ thick Si-doped AlGaN carrier supply layer, and a $5 \mathrm{~nm}$ undoped AlGaN barrier layer, grown on top of GaN buffer. The doping levels were $2 \times 10^{18}, 5 \times 10^{18}$, and $1 \times 10^{19} \mathrm{~cm}^{-3}$. In the case of the $1 \times 10^{19} \mathrm{~cm}^{-3}$ doped structure on $\mathrm{Si}$ as well as structures on $\mathrm{SiC}$ a $3 \mathrm{~nm}$ undoped $\mathrm{GaN}$ cap was then grown. All AlGaN layers have an Al content of $x_{\mathrm{AlN}} \cong 0.28$.

van der Pauw patterns with an active area of 0.3 $\times 0.3 \mathrm{~mm}^{2}$ were processed simultaneously to the HEMT devices. Ohmic contact was prepared by evaporating layered $\mathrm{Ti} / \mathrm{Al} / \mathrm{Ni} / \mathrm{Au}$ followed by annealing at $850{ }^{\circ} \mathrm{C}$ for $30 \mathrm{~s}$ in $\mathrm{N}_{2}$ ambient. Room temperature conductivity and Hall effect measurements were performed on the same sample before and after $\mathrm{Si}_{3} \mathrm{~N}_{4}$ passivation. Plasma-enhanced chemical vapor deposition at $300{ }^{\circ} \mathrm{C}$ was used to prepare 100 and $150 \mathrm{~nm}$ thick $\mathrm{Si}_{3} \mathrm{~N}_{4}$ layer on samples with $\mathrm{Si}$ and $\mathrm{SiC}$ substrates, respectively. The layer thickness and refraction coefficient were controlled by ellipsometry. In some cases also $\sim 5$ $\times 5 \mathrm{~mm}^{2}$ samples with alloyed In contacts were used; the data obtained are consistent, within measurement error, with those found on patterned "small" samples.

TABLE I. Sheet carrier density, electron mobility, and sheet resistivity of $\mathrm{AlGaN} / \mathrm{GaN}$ heterostructures on $\mathrm{Si}$ substrates before and after passivation.

\begin{tabular}{ccccc}
\hline \hline $\begin{array}{c}N_{D} \\
\left(\mathrm{~cm}^{-3}\right)\end{array}$ & Passivation & $\begin{array}{c}n_{s} \\
\left(10^{12} \mathrm{~cm}^{-2}\right)\end{array}$ & $\begin{array}{c}\mu_{n} \\
\left(\mathrm{~cm}^{2} / \mathrm{V} \mathrm{s}\right)\end{array}$ & $\begin{array}{c}R_{s} \\
(\Omega / \mathrm{sq})\end{array}$ \\
\hline undoped & yes & 7.12 & 1150 & 762 \\
undoped & no & 9.13 & 1080 & 631 \\
$2 \times 10^{18}$ & yes & 7.98 & 1235 & 638 \\
$2 \times 10^{18}$ & no & 9.81 & 1160 & 558 \\
$5 \times 10^{18}$ & yes & 8.76 & 1173 & 610 \\
$5 \times 10^{18}$ & no & 9.57 & 1093 & 579 \\
$1 \times 10^{19}$ & yes & 9.20 & 1270 & 534 \\
$1 \times 10^{19}$ & no & 9.86 & 1220 & 521 \\
\hline \hline
\end{tabular}


TABLE II. Sheet carrier density, electron mobility, and sheet resistivity of $\mathrm{AlGaN} / \mathrm{GaN}$ heterostructures on SiC substrates before and after passivation.

\begin{tabular}{ccccc}
\hline \hline $\begin{array}{c}N_{D} \\
\left(\mathrm{~cm}^{-3}\right)\end{array}$ & Passivation & $\begin{array}{c}n_{s} \\
\left(10^{12} \mathrm{~cm}^{-2}\right)\end{array}$ & $\begin{array}{c}\mu_{n} \\
\left(\mathrm{~cm}^{2} / \mathrm{V} \mathrm{s}\right)\end{array}$ & $\begin{array}{c}R_{s} \\
(\Omega / \mathrm{sq})\end{array}$ \\
\hline undoped & yes & 6.95 & 1930 & 466 \\
undoped & no & 8.21 & 1773 & 430 \\
undoped & yes & 7.77 & 1900 & 423 \\
undoped & no & 9.36 & 1725 & 387 \\
$2 \times 10^{18}$ & yes & 9.32 & 1590 & 422 \\
$2 \times 10^{18}$ & no & 10.2 & 1490 & 410 \\
$5 \times 10^{18}$ & yes & 10.8 & 1430 & 404 \\
$5 \times 10^{18}$ & no & 11.4 & 1355 & 405 \\
\hline \hline
\end{tabular}

The sheet carrier density, electron mobility, and sheet resistivity measured before and after passivation are shown in Tables I and II. The sheet carrier density in unpassivated samples is $7-11 \times 10^{12} \mathrm{~cm}^{-2}$ and it increases slightly with an increase in the level of doping. A well resolved increase of the carrier density after passivation is found in all samples investigated. The passivation-induced sheet charge decreases with an increase in the doping level from 1.5-2 $\times 10^{12} \mathrm{~cm}^{-2}$ on undoped samples to $0.7 \times 10^{12} \mathrm{~cm}^{-2}$ on $5-10 \times 10^{18} \mathrm{~cm}^{-3}$ doped samples, as shown in Fig. 1. The relative change in sheet carrier density after passivation, shown in Fig. 2, confirms lower impact of passivation on samples with higher doping. The electron mobility in unpassivated samples on $\mathrm{SiC}$ substrates decreases with an increase in doping (from $1900 \mathrm{~cm}^{2} / \mathrm{V} \mathrm{s}$ on undoped samples to 1430 $\mathrm{cm}^{2} / \mathrm{V}$ s on the $5 \times 10^{18} \mathrm{~cm}^{-3}$ doped sample) and in samples on $\mathrm{Si}$ substrates it is nearly the same $\left(\mu_{H} \cong 1200 \mathrm{~cm}^{2} / \mathrm{V} \mathrm{s}\right)$. The influence of passivation on the electron mobility is less pronounced than that on the carrier density. Slightly lower mobilities than before passivation (less than a $10 \%$ decrease) were evaluated on all passivated samples (see Tables I and II). The relative change in mobility after passivation of intentionally undoped and doped samples is shown in Fig. 2.

Usually it is suggested that passivation of $\mathrm{AlGaN} / \mathrm{GaN}$ heterostructures reduces the surface trap density. According to our results, the number of electrons trapped on the unpassivated surface, which is proportional to the passivation-

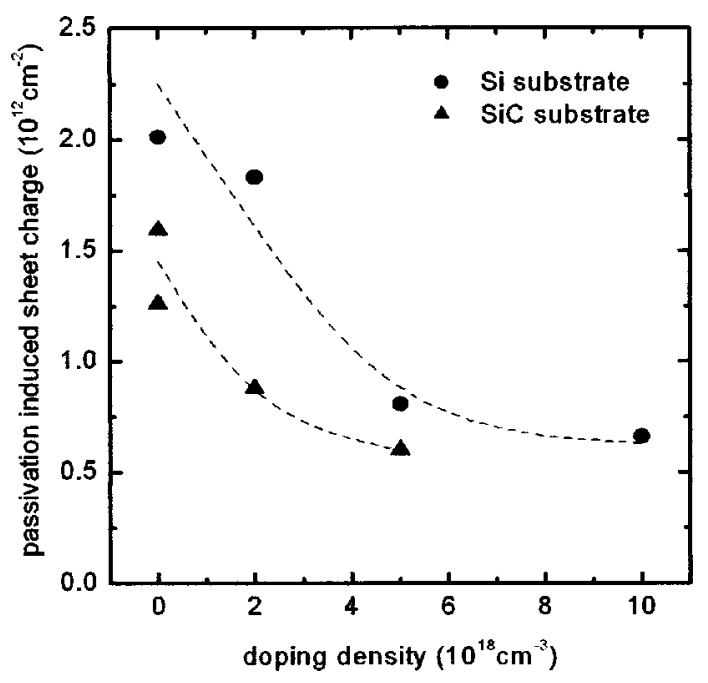

FIG. 1. Passivation-induced sheet carrier density in intentionally undoped and doped $\mathrm{AlGaN} / \mathrm{GaN}$ heterostructures grown on $\mathrm{Si}$ and $\mathrm{SiC}$ substrates. The lines are a guide for the eye. The lines are a guide for the eye.
Downloaded 21 Dec 2006 to 134.94.122.39. Redistribution subject to AIP license or copyright, see http://apl.aip.org/apl/copyright.jsp

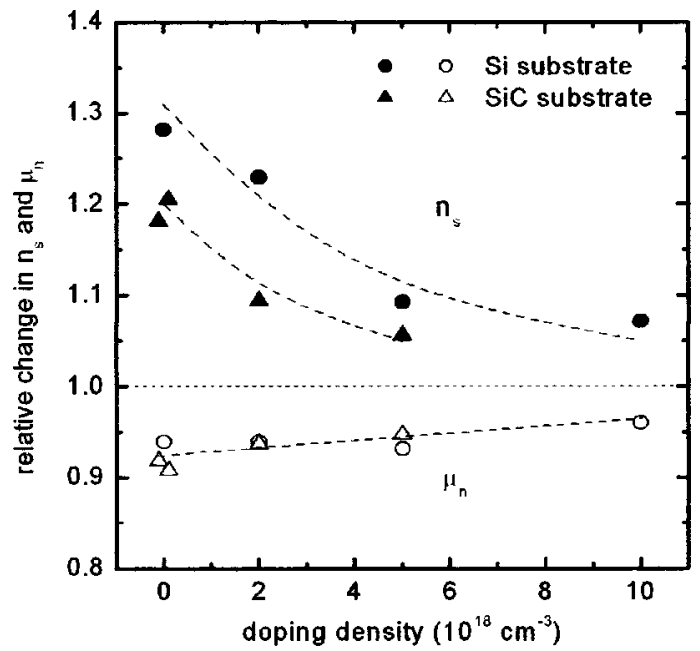

FIG. 2. Relative change in sheet carrier density and electron mobility of intentionally undoped and doped $\mathrm{AlGaN} / \mathrm{GaN}$ heterostructures after $\mathrm{Si}_{3} \mathrm{~N}_{4}$ passivation. The lines are a guide for the eye.

induced carrier density, decreases with an increase in the doping level. This conclusion can be supported by recent observations of unpassivated devices where the rf dispersion in doped AlGaN/GaN HEMTs is significantly reduced in comparison to their undoped counterparts. ${ }^{11,12}$ Another explanation for the results obtained can be made by considering stress-induced effects due to passivation. It is well known that deposition of dielectric layers like $\mathrm{SiO}_{2}$ and $\mathrm{Si}_{3} \mathrm{~N}_{4}$ produces residual stress that can range from tensile to compressive (up to $\pm 1 \mathrm{GPa}$ ), depending on the process conditions. ${ }^{13}$ Recently it was reported that passivation changes in AlGaN/ GaN HEMT performance can be explained by stress-induced polarization charge $\mathrm{e}^{14}$ and depend strongly on the amount of stress produced by different deposition conditions. ${ }^{15}$ Thus, the passivation-induced increase of the sheet carrier density in the samples investigated follows from an additional piezoelectric field created by $\mathrm{Si}_{3} \mathrm{~N}_{4}$ passivation. Lower impact of passivation on more highly doped samples follows from the lower piezoresistivity of more highly doped samples. ${ }^{16}$ The slightly different impact of passivation on the samples on $\mathrm{Si}$ and $\mathrm{SiC}$ substrates can be explained by differences in $\mathrm{Si}_{3} \mathrm{~N}_{4}$ thickness and thus by differences in stress induced. ${ }^{13}$ Experiments to answer this question are in progress.

The channel conductivity of AlGaN/GaN heterostructures on $\mathrm{Si}$ and $\mathrm{SiC}$ substrates before and after passivation is shown in Fig. 3. For unpassivated samples the channel conductivity increases with an increase in the doping density. After passivation, a well resolved increase of channel conductivity is observed on undoped or lightly doped samples, but nearly the same channel conductivity results on highly doped samples. From this it follows that the passivation impact on higher doped AlGaN/GaN heterostructures is less pronounced than on undoped or lightly doped ones.

In conclusion, we performed conductivity and Hall effect measurements on intentionally undoped and doped $\mathrm{AlGaN} / \mathrm{GaN}$ heterostructures before and after passivation. An increase of the sheet carrier density (up to $~ 30 \%$ ) and a slight decrease of the electron mobility (less than 10\%) were found for all samples after passivation. The passivationinduced sheet carrier density is $1.5-2 \times 10^{12} \mathrm{~cm}^{-2}$ on un-
AIP license or copyright, see http://apl.aip.org/apl/copyright.jsp 


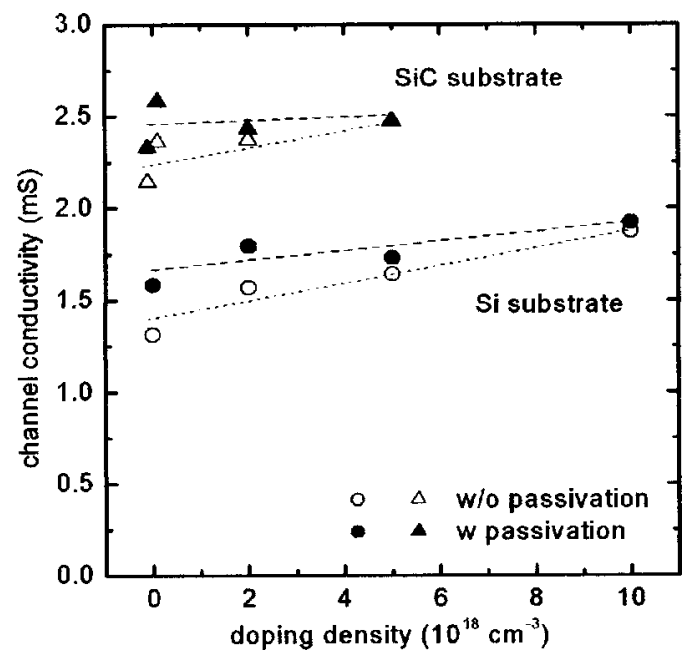

FIG. 3. Impact of $\mathrm{Si}_{3} \mathrm{~N}_{4}$ passivation on the channel conductivity in intentionally undoped and doped $\mathrm{AlGaN} / \mathrm{GaN}$ heterostructures grown on $\mathrm{Si}$ and $\mathrm{SiC}$ substrates. The lines are a guide for the eye.

doped samples and only $0.7 \times 10^{12} \mathrm{~cm}^{-2}$ on $5-10$ $\times 10^{18} \mathrm{~cm}^{-3}$ doped samples. The channel conductivity of undoped or lightly doped samples increases after passivation, but nearly the same channel conductivity results on highly doped samples.

The authors thank Y. Dikme of the Technical University of Aachen and M. Heuken of AIXTRON AG, Aachen, for samples on $\mathrm{Si}$ substrates and J. Flynn and G. Brandes of ATMI for samples on SiC substrates.

${ }^{1}$ S. C. Binari, W. Kruppa, H. B. Dietrich, G. Kelner, A. E. Wickenden, and J. A. Freitas, Solid-State Electron. 41, 1549 (1997).

${ }^{2}$ S. Trassaert, B. Boudart, C. Gaquiere, D. Theron, Y. Crosnier, F. Huet, and M. A. Poisson, Electron. Lett. 35, 1386 (1999).

${ }^{3}$ B. M. Greene, K. K. Chu, E. M. Chumbes, J. A. Smart, J. R. Shealy, and L. F. Eastman, IEEE Electron Device Lett. 21, 268 (2000).

${ }^{4}$ G. Koely, V. Tilak, L. F. Eastman, and M. G. Spencer, IEEE Trans. Electron Devices 50, 886 (2003).

${ }^{5}$ I. Harrison, W. Clayton, and W. Jeffs, Phys. Status Solidi A 188, 275 (2001).

${ }^{6}$ W. S. Tan, P. A. Houston, P. J. Parbrook, G. Hill, and R. J. Airey, J. Phys. D 35, 595 (2002).

${ }^{7}$ W. Lu, V. Kumar, R. Schwindt, E. Piner, and I. Adesida, Solid-State Electron. 46, 1441 (2002).

${ }^{8}$ B. Luo, R. Mehandru, J. Kim, F. Ren, B. P. Gila, A. H. Onstine, C. R. Abernathy, S. J. Pearton, R. Fitch, J. Gillespie, T. Jenkins, J. Sewell, D. Via, A. Crespo, and Y. Irokawa, J. Electrochem. Soc. 149, G613 (2002).

${ }^{9}$ X. Z. Dang, E. T. Yu, E. J. Piner, and B. T. McDermott, J. Appl. Phys. 90, 1357 (2001).

${ }^{10}$ P. Javorka, J. Bernát, A. Fox, M. Marso, H. Lüth, and P. Kordoš, Electron. Lett. 39, 1155 (2003).

${ }^{11}$ O. Mitrofanov, M. Mandra, and N. Weimann, Appl. Phys. Lett. 82, 4361 (2003).

${ }^{12}$ J. Bernát, P. Javorka, A. Fox, M. Marso, H. Lüth, and P. Kordoš, SolidState Electron. 47, 2097 (2003)

${ }^{13}$ S. M. Hu, J. Appl. Phys. 70, R53 (1991).

${ }^{14}$ A. Conway, P. Asbeck, and J. Moon, 45th Electronic Material Conference, Salt Lake City, UT, June 2003, Abstracts book, TMS, p. 85.

${ }^{15}$ W. S. Tan, P. A. Houston, G. Hill, M. W. Low, P. J. Parbrook, and R. J. Airey, in Ref. 14, p. 84.

${ }^{16}$ M. Eickhoff, O. Ambacher, G. Krötz, and M. Stutzmann, J. Appl. Phys. 90, 3383 (2001). 